\title{
Stability and Interconversion of Acetylcholine Conformers
}

\author{
Jae Shin Lee* and Young Choon Park ${ }^{\dagger, a}$ \\ Department of Chemistry, Ajou University, Suwon 443-749, Korea. "E-mail: jsnlee@ajou.ac.kr \\ 'Department of Chemistry, Korea Advanced Institute of Science and Technology (KAIST), Daejeon 305-701, Korea \\ Received March 20, 2014, Accepted June 4, 2014
}

\begin{abstract}
The gas phase structures, energetics, and interconversion pathways of five lowest energy conformers of acetylcholine were examined employing the B3LYP, MP2, and $\operatorname{CCSD}(\mathrm{T})$ methods in conjunction with diverse basis sets including the correlation consistent aug-cc-pVDZ and aug-cc-pVTZ basis sets. It is found that use of adequate basis set containing proper polarization and diffuse functions capable of describing the floppy potential energy surface of acetylcholine is important in correctly predicting the relative stability of these conformers. The interconversion pathways and barrier heights between these conformers were elucidated by examining the potential energy surface for torsional motion, which also manifested the presence of chiral conformations of acetylcholine corresponding to the original conformations. On the basis of high level electronic energy calculations and thermal contribution analysis, four lowest energy conformers appear to be populated in the energy range of less than $1 \mathrm{kcal} / \mathrm{mol}$ at room temperature.
\end{abstract}

Key Words : Acetylcholine conformers, Stability, Interconversion

\section{Introduction}

Acetylcholine (2-Acetoxy- $N, N, N$-trimethylethanaminium) is an important neurotransmitter found in the peripheral and central nervous systems of vertebrate including humans ${ }^{1}$ and its conformational structure is crucial to understand the molecular recognition between the acetylcholine and its receptors in nervous system. ${ }^{2}$ It also serves as a mediator for parasympathetic function of the autonomic nerve system. ${ }^{3}$ Despite its importance and wide use in nervous system, however, the stable conformer structures of acetylcholine and their interconversion pathways, either in gas phase or in aqueous solution, were not well elucidated up to date.

This paper focuses on the accurate gas phase energetics and interconversion pathways of low energy conformers of positively charged acetylcholine ion using high level $a b$ initio theoretical models. Although previous quantum theoretical studies ${ }^{4-11}$ indicated the presence of low energy zone depending upon orientation of acetoxy group in the system where stable conformations could be identified in the potential energy surface (PES) of acetylcholine, the energy differences between these conformations and interconversion mechanism could not be delineated as most of these previous studies employed the semiempirical and low level $a b$ initio methods while the PES of acetylcholine is expected to be floppy. Another motivation for the present study is concerned with a recent experimental and theoretical study of the infrared multiphoton dissociation (IRMPD) spectrum of this ion, where analysis of spectral peaks was performed in terms of contributions from relevant low energy conformers. ${ }^{11}$

aPresent address: Department of Chemistry, University of Calgary, Calgary AB T2N-1N4, Canada
Previous theoretical studies on acetylcholine ion using DFT and MP2 methods ${ }^{9-11}$ have suggested that it could have four or five stable conformers within a few kilocalorie energy range and some of them appear to be close-lying, possibly within $1-2 \mathrm{kcal} / \mathrm{mol}$. It has to be noted, however, that the energy difference of this small magnitude cannot be reliably predicted without proper account of electron correlation and basis set extension effect on relative energies between various conformations involved. Therefore, to determine the relative stability of low energy conformers accurately and to understand the conformational interconversion pathways between these close-lying conformers, we here employ more sophisticated theoretical models than used previously which must be able to manifest proper electron correlation and basis set extension effect on floppy potential energy surface of acetylcholine ion. In the present study we employ the $\mathrm{MP}^{12}$ and $\operatorname{CCSD}(\mathrm{T})^{13}$ methods as well as B3LYP ${ }^{14-17}$ method in conjunction with large basis sets to elucidate the energetics and interconversion pathways of close-lying conformers of this important species, which could also help us interpret the aforementioned IRMPD spectrum of acetylcholine correctly.

This paper is organized as follows. In the next section details of computational methods employed in this study are explained. In section III, the results of our computations and discussions about the results are presented, especially in relation to the spectral features of recently reported IRMPD spectrum of acetylcholine. Conclusion is in the final section.

\section{Computational Details}

To investigate the effect of electron correlation and basis set on the conformer structures and energetics of the aforementioned five lowest energy conformers (four of them 
considered to be within close energy range) of acetylcholine ion, three representative electron correlation methods, $a b$ initio $\mathrm{MP} 2^{12}$ and $\mathrm{CCSD}(\mathrm{T})$ methods $^{13}$ as well as B3LYP mrthod ${ }^{14-17}$ from density functional theory ${ }^{18}$ were employed in this study along with diverse basis sets including $6-31 \mathrm{G}^{*}$, $6-311++\mathrm{G}^{* *}$ and correlation consistent basis sets aug-ccpVDZ and aug-cc-pVTZ. ${ }^{19,20}$ To examine the effect of diffuse functions on the optimized geometries of acetylcholine, we also employed the aug'-cc-pVDZ and aug'-cc-pVTZ sets which were constructed by removing the diffuse functions for hydrogen atom from the aug-cc-pVDZ and aug-cc-pVTZ sets, respectively. The largest basis set, aug-cc-pVTZ set, employed in this study is composed of $[4 \mathrm{~s} 3 \mathrm{p} 2 \mathrm{~d} / 5 \mathrm{~s} 4 \mathrm{p} 3 \mathrm{~d} 2 \mathrm{f}]$ contracted functions.

After geometry optimization for each conformation, frequency calculations were performed to evaluate the thermal (Gibbs free energy) contributions to the electronic energy differences between various conformers. The frequency calculation results were also utilized to simulate the infrared spectrum of each conformer, which was compared with the experimental IRMPD spectrum for identification of contributions to the spectral structures of individual conformer. The transition states connecting various conformer structures were obtained by using various transition state optimization algorithms and verifying the first order saddle points of the transition structures through frequency calculations. To make sure the obtained transition structure is corresponding to the transition state connecting the desired initial and final conformer structures, intrinsic reaction coordinate (IRC) calculations ${ }^{21,22}$ were performed in both forward and reverse directions from the transition structure obtained. All correlated calculations were performed under the frozen core approximation. All calculations were performed using Gaussian program package. ${ }^{23}$

\section{Results and Discussion}

In Figure 1 the geometries of the five conformers of acetylcholine ion considered in this study (denoted $\mathrm{C}_{1}$ through $\mathrm{C}_{5}$ ) at the MP2/aug-cc-pVTZ optimization level are shown along with the dihedral angles $\theta_{1}(\mathrm{~N}(7)-\mathrm{C}(6)-\mathrm{C}(5)-$ $\mathrm{O}(4))$ and $\theta_{2}(\mathrm{C}(6)-\mathrm{C}(5)-\mathrm{O}(4)-\mathrm{C}(2))$, which represent the major structural features of acetylcholine as the acetoxy group is planar. In the case of $\theta_{1}$ for $C_{2}$ and $\theta_{2}$ for $C_{3}$ conformation, the MP2/aug-cc-pVTZ dihedral angles differ from the dihedral angles at the B3PW91/6-311++ $\mathrm{G}^{* *}$ level $^{11}$ by $10^{\circ}$ and $7^{\circ}$, respectively, suggesting the order of stability of the conformers at the MP2/aug-cc-pVTZ level could be different from the results at the lower level of theory such as $\mathrm{B} 3 \mathrm{LYP} / 6-31 \mathrm{G}^{*}$ or B3PW91/6-311++ $\mathrm{G}^{* *}{ }^{* 11}$ This is well demonstrated in Table 1, where relative electronic energies $(\Delta \mathrm{E})$ of the other conformers with respect to $\mathrm{C}_{1}$ conformer at various levels of theory are presented.

The first noticeable feature in Table 1 is that $\Delta \mathrm{E}$ results are sensitive to the electron correlation method and basis set employed, especially to the quality of basis set. It is manifested that, regardless of electron correlation method adopted,

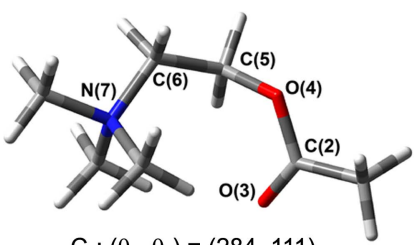

$\mathrm{C}_{1}:\left(\theta_{1}, \theta_{2}\right)=(284,111)$

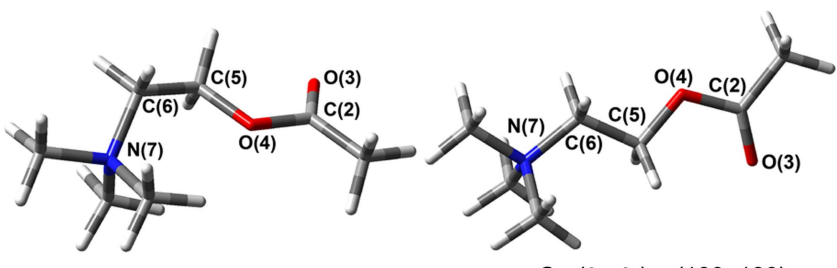

$\mathrm{C}_{3}:\left(\theta_{1}, \theta_{2}\right)=(299,187)$

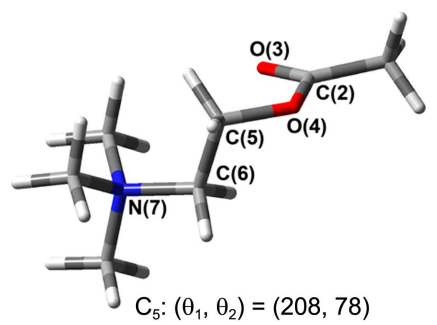

Figure 1. Geometries of five conformers $\left(\mathrm{C}_{1}-\mathrm{C}_{5}\right)$ of acetylcholine ion examined in this work. $\left(\theta_{1}, \theta_{2}\right)$ are $\mathrm{N}(7)-\mathrm{C}(6)-\mathrm{C}(5)-\mathrm{O}(4)$ and $\mathrm{C}(6)-\mathrm{C}(5)-\mathrm{O}(4)-\mathrm{C}(2)$ torsion angles at the MP2/aug-cc-pVTZ level, respectively.

employment of basis sets larger than the $6-311++\mathrm{G}^{* *}$ set appears necessary to correctly predict the order of stability of these conformers of acetylcholine ion. It is worth noting that with large basis sets such as the aug-cc-pVDZ (or aug'cc-pVDZ) and aug-cc-pVTZ (or aug'-cc-pVTZ), B3LYP, $\mathrm{MP} 2$, and $\operatorname{CCSD}(\mathrm{T})$ results all predict that the electronic energy of $\mathrm{C}_{5}$ is lower than that of $\mathrm{C}_{3}$, in contrast to the results with smaller basis sets. The energy difference between these two conformers $\left(\mathrm{C}_{3}\right.$ and $\left.\mathrm{C}_{5}\right)$ appears to amount to 0.7 (MP2/ aug-cc-pVTZ result)-1.0 (CCSD(T)/aug'-cc-pVDZ result) $\mathrm{kcal} / \mathrm{mol}$, although DFT results (B3LYP/aug-cc-pVDZ) ex-

Table 1. Relative electronic energies of acetylcholine conformers with respect to $C_{1}$ at various levels of theory (in $\mathrm{kcal} / \mathrm{mol}$ )

\begin{tabular}{|c|c|c|c|c|}
\hline Method & $\mathrm{C}_{2}$ & $\mathrm{C}_{3}$ & $\mathrm{C}_{4}$ & $\mathrm{C}_{5}$ \\
\hline B3LYP/6-31G* & 1.1 & 1.7 & 4.1 & 2.0 \\
\hline $\mathrm{MP} 2 / 6-31 \mathrm{G}^{*}$ & 0.5 & 1.4 & 4.6 & 1.9 \\
\hline $\mathrm{CCSD} / 6-31 \mathrm{G}^{*}$ & 0.4 & 1.3 & 4.1 & 1.5 \\
\hline B3LYP/6-311++G ${ }^{* *}$ & 0.6 & 0.8 & 2.7 & 1.2 \\
\hline B3LYP/aug-cc-pVDZ & 0.7 & 1.3 & 2.8 & 0.9 \\
\hline $\mathrm{MP} 2 / 6-311++\mathrm{G}^{* *}$ & 0.2 & 0.8 & 3.5 & 1.0 \\
\hline MP2/aug'-cc-pVDZ ${ }^{a}$ & 0.5 & 1.7 & 4.2 & 1.0 \\
\hline MP2/aug-cc-pVDZ & 0.6 & 2.0 & 4.5 & 1.2 \\
\hline MP2/aug'-cc-pVTZ ${ }^{a}$ & 0.7 & 1.7 & 4.0 & 1.0 \\
\hline MP2/aug-cc-pVTZ & 0.8 & 1.8 & 4.2 & 1.1 \\
\hline $\operatorname{CCSD}(\mathrm{T}) / 6-311++\mathrm{G}^{* * b}$ & 0.2 & 0.8 & 3.3 & 0.7 \\
\hline $\operatorname{CCSD}(\mathrm{T}) /$ aug'-cc-pVDZ $^{b}$ & 0.6 & 1.8 & 4.0 & 0.8 \\
\hline
\end{tabular}

${ }^{a}$ Basis sets contain diffuse functions for heavy atoms only except hydrogen. ${ }^{b} \mathrm{MP} 2 /$ aug-cc-pVTZ optimized geometries were used. 
Table 2. Basis set effect of relative electronic energies of acetylcholine conformers with respect to $\mathrm{C}_{1}$ at the MP2 level ${ }^{a}$ (in kcal/ mol)

\begin{tabular}{lcccc}
\hline Basis set & $\mathrm{C}_{2}$ & $\mathrm{C}_{3}$ & $\mathrm{C}_{4}$ & $\mathrm{C}_{5}$ \\
\hline 6-311++G $^{* *}$ & $0.1(0.2)^{b}$ & $0.7(0.8)$ & $3.4(3.5)$ & $0.9(1.0)$ \\
aug'-cc-pVDZ $^{\prime}$ & $0.5(0.5)^{b}$ & $1.7(1.7)$ & $4.2(4.2)$ & $1.0(1.0)$ \\
aug-cc-pVDZ & 0.6 & 2.0 & 4.5 & 1.2 \\
aug'-cc-pVTZ & 0.7 & 1.7 & 4.4 & 1.0 \\
aug-cc-pVTZ & 0.8 & 1.8 & 4.2 & 1.1 \\
\hline
\end{tabular}

${ }^{a}$ Geometries optimized at the MP2/aug-cc-pVTZ are used throughout. ${ }^{b}$ Values in parentheses represent the results at the geometries optimized at the MP2/6-311++G* level.

Table 3. Sum of electronic ${ }^{a}$ and Gibbs free energy contributions for acetylcholine conformers ${ }^{b}$ at various levels of theory (in $\mathrm{kcal} / \mathrm{mol}$ )

\begin{tabular}{|c|c|c|c|c|}
\hline Method & $\mathrm{C}_{2}$ & $\mathrm{C}_{3}$ & $\mathrm{C}_{4}$ & $\mathrm{C}_{5}$ \\
\hline $\mathrm{B} 3 \mathrm{LYP} / 6-31 \mathrm{G}^{*}$ & -0.6 & 0.2 & 1.6 & -0.6 \\
\hline B3LYP/6-311++G ${ }^{* *}$ & -0.6 & 0.3 & 1.4 & -0.3 \\
\hline MP2/6-31G ${ }^{*}$ & -0.4 & 0.8 & 1.9 & 0.1 \\
\hline MP2/6-311++G* & 0.1 & 0.8 & 3.2 & 0.4 \\
\hline MP2/aug'-cc-pVDZ & 0.0 & 0.7 & 1.9 & 0.4 \\
\hline
\end{tabular}

${ }^{a}$ Electronic energies were taken from the CCSD(T)/aug'-cc-pVDZ results in Table $1 .{ }^{b}$ All energies with respect to the energies for $\mathrm{C}_{1}$ conformer.

hibit smaller difference $(\sim 0.4 \mathrm{kcal} / \mathrm{mol})$.

Table 2 shows more clearly how the relative stability of acetylcholine conformers can be affected by the size of basis set at the MP2 level. As the basis set becomes larger, the energy difference between $C_{1}$ and $C_{2}$ becomes larger, making $\mathrm{C}_{1}$ clearly the most stable conformation as well as reversing the order of stability between $\mathrm{C}_{3}$ and $\mathrm{C}_{5}$ conformers for this ion. It is interesting to note that the results with the aug'cc-pVDZ set are similar to the results with the aug-cc-pVTZ set, suggesting the utility of the aug'-cc-pVDZ basis set in case use of more extensive basis set is not feasible.

In Table 3 sum of Gibbs free energy contributions (computed at $298 \mathrm{~K}$ ) to the reference electronic energies of each conformer, which were taken as the results at the $\operatorname{CCSD}(\mathrm{T}) /$ aug'-cc-pVDZ level in Table 1, is presented. Although the thermal contribution results are different depending on the theoretical model employed, it is manifested that the energy of $\mathrm{C}_{3}$ conformer is higher than that of $\mathrm{C}_{1}$ ( or $\mathrm{C}_{2}$ or $\mathrm{C}_{5}$ ), making $\mathrm{C}_{1}, \mathrm{C}_{2}$ and $\mathrm{C}_{5}$ most stable conformations for acetylcholine ion. The order of stability between these conformers $\left(\mathrm{C}_{1}, \mathrm{C}_{2}\right.$ and $\left.\mathrm{C}_{5}\right)$ is not clear due to the strong dependence of thermal energy contribution results on the theoretical model employed, even though the large basis set calculations at the MP2 level appear to suggest $\mathrm{C}_{1}$ or $\mathrm{C}_{2}$ conformer as the lowest energy conformer for this ion.

Given the energy differences between the various conformers of acetylcholine ion, it would be interesting to investigate the transition states and barrier heights connecting these conformations. For this purpose, transition state optimizations were performed at the MP2/6-311++G $\mathrm{G}^{* *}$ level and the barrier heights were computed both at the MP2/6-311++ $\mathrm{G}^{* *}$ and MP2/aug'-cc-pVDZ levels. The stationary points obtained
Table 4. Barrier heights between various conformers of acetylcholine (in $\mathrm{kcal} / \mathrm{mol}$ )

\begin{tabular}{ccc}
\hline \multirow{2}{*}{$\begin{array}{c}\text { Transition state } \\
\text { (initial-final state) }\end{array}$} & \multicolumn{2}{c}{ Barrier heights $^{a}$} \\
\cline { 2 - 3 } & $\mathrm{MP} 2 / 6-311++\mathrm{G}^{* *}$ & MP2/aug'-cc-pVDZ $^{b}$ \\
\hline $\mathrm{C}_{1}-\mathrm{C}_{3}$ & $1.6(0.9)^{c}$ & $2.1(0.4)$ \\
$\mathrm{C}_{2}-\mathrm{C}_{3}$ & $1.6(1.0)$ & $1.9(0.7)$ \\
$\mathrm{C}_{1}-\mathrm{C}_{5}$ & $3.1(2.2)$ & $3.1(2.1)$ \\
$\mathrm{C}_{2}-\mathrm{C}_{5}{ }^{\prime}$ & $3.0(2.1)$ & $2.7(2.3)$ \\
\hline
\end{tabular}

${ }^{a}$ Barrier heights with respect to the energies of the initial state conformers. ${ }^{b}$ Barrier heights computed with the MP2/6-311++G ${ }^{* *}$ geometries. ${ }^{c}$ Values in parentheses are the barrier heights with respect to the energies of the final state conformers.

were checked to yield only one imaginary frequency at the optimized geometries by frequency calculations. Finally, to make sure the optimized geometries obtained by this procedure are the desired transition state geometries connecting the two conformers of interest, intrinsic reaction coordinate calculations ${ }^{21,22}$ were carried out in forward and reverse directions beginning from the optimized transition state geometries.

In Table 4 and Figure 2 the barrier heights between various conformers containing $\mathrm{C}_{1}, \mathrm{C}_{2}, \mathrm{C}_{3}$, and $\mathrm{C}_{5}$ conformers and potential energy surface along conformational change pathways $\left(\theta_{1}\right.$ and $\left.\theta_{2}\right)$ are presented. It is interesting to note from Figure 2 that there are no direct pathways connecting $\mathrm{C}_{1}-\mathrm{C}_{2}$ and $\mathrm{C}_{3}-\mathrm{C}_{5}$ transitions, for which $\mathrm{C}_{3}$ and $\mathrm{C}_{1}$ conformers play a role as an intermediate state, respectively. One important feature in Figure 2 is that, due to the symmetry of acetylcholine, there exist unsuperimposable mirror image conformers (represented as $\mathrm{C}_{1}{ }^{\prime}, \mathrm{C}_{2}{ }^{\prime}, \mathrm{C}_{3}^{\prime}$, and $\mathrm{C}_{5}{ }^{\prime}$ ) for $\mathrm{C}_{1}, \mathrm{C}_{2}$, $\mathrm{C}_{3}$, and $\mathrm{C}_{5}$ conformers. The chirality of these two types of conformers is clearly seen in their IR and vibrational circular dichroism spectra in Figure 3. Thus, it is much easier for $\mathrm{C}_{2}$ conformer to change its conformation to $\mathrm{C}_{5}$ than $\mathrm{C}_{5}$. If the barrier for $\mathrm{C}_{2}-\mathrm{C}_{5}$ ' conformational change were significantly high for acetylcholine, these two types of conformers would be enantiomers separable at room temperature. However, the

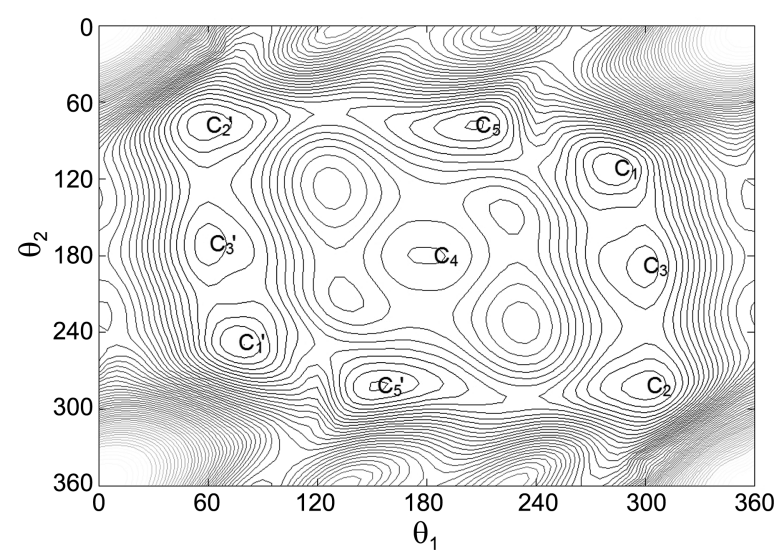

Figure 2. Potential energy surface along $\theta_{1}$ and $\theta_{2}$ at the MP2/6$311++\mathrm{G}^{* *}$ level. The energy points in this plot were obtained by optimizing all the geometric parameters except two dihedral angles $\left(\theta_{1}, \theta_{2}\right)$. The contour interval is $0.5 \mathrm{kcal} / \mathrm{mol}$. 

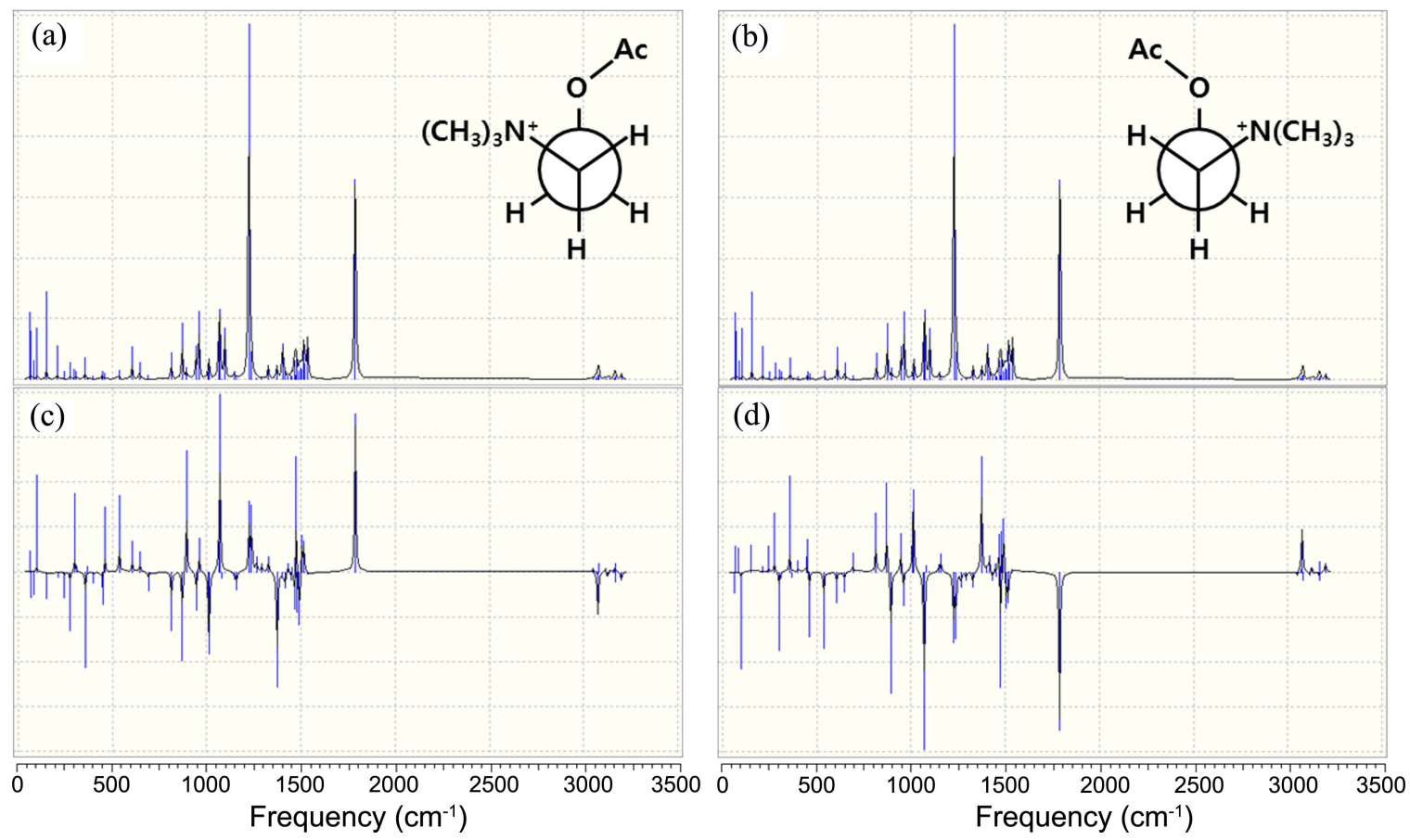

Figure 3. (a) IR spectrum of $C_{1}$ conformer (b) IR spectrum of $C_{1}{ }^{\prime}$ conformer (c) VCD spectrum of $C_{1}$ conformer (d) VCD spectrum of $C_{1}{ }^{\prime}$ conformer. $\mathrm{Y}$ axis represents the peak intensity.

actual barrier height between $\mathrm{C}_{2}-\mathrm{C}_{5}$ ' conformational change in Table 4 suggests these two types of conformers would be difficult to separate at most temperatures of biological interest. Chirality in the absence of asymmetric carbon in the system has been known for other systems. ${ }^{24,25}$

From the results in Table 3 and Table 4 it appears that $C_{1}$, $\mathrm{C}_{2}$ and $\mathrm{C}_{5}$ conformers (compared to $\mathrm{C}_{3}$ and $\mathrm{C}_{4}$ conformers) would be dominantly populated at room temperature and IR spectrum of acetylcholine would exhibit the spectral features representing the contributions from these conformers. However, spectral contributions from $\mathrm{C}_{3}$ conformer also may not be negligible as the energy difference between $C_{3}$ and $C_{1}$ (or $\mathrm{C}_{2}$ ) appears to be small and the barrier heights from $\mathrm{C}_{3}$ to $\mathrm{C}_{1}$ or $\mathrm{C}_{2}$ appear to be higher than $\mathrm{kT}$ at room temperature. Therefore, it appears that the spectral features of IR spectrum for acetylcholine would have major contributions from these conformers.

Recently, Seydou et al. reported an IRMPD spectrum of acetylcholine ion between $800 \mathrm{~cm}^{-1}$ and $2000 \mathrm{~cm}^{-1}$ with assignment of peaks corresponding to stretching vibrations of backbone atoms in the acetylcholine conformers. ${ }^{11}$ The assignment was made by assuming $\mathrm{C}_{1}, \mathrm{C}_{2}$, and $\mathrm{C}_{3}$ conformers make most contributions to the spectral structures, which was based on molecular dynamics calculations at the $\mathrm{HF} / 6-31 \mathrm{G}^{*}$ level and simulation results of IR spectra of acetylcholine ion at the B3PW91/6-311++ $\mathrm{G}^{* *}$ level. In view of the more accurate quantum chemical calculation results obtained in this work, however, it appears necessary to consider the contribution from $\mathrm{C}_{5}$ conformer as well as contributions from $\mathrm{C}_{1}, \mathrm{C}_{2}$, and $\mathrm{C}_{3}$ conformers to the spectral features in the IRMPD spectrum of acetylcholine ion for correct assignment of contributions from various conformers. For this purpose, we simulated the IR spectra of various conformers of acetylcholine ion at different levels of theory and identified the vibration frequencies having $\mathrm{C}(2)-\mathrm{O}(3)$ and $\mathrm{C}(2)-\mathrm{O}(4)$ stretching vibration as major contribution, respectively (see Fig. 1 for identification of relevant backbone atoms). Table 5 shows the aforementioned stretching frequencies at various levels of theory.

In the case of $\mathrm{C}(2)-\mathrm{O}(3)$ stretching vibration for which

Table 5. Stretching vibration frequencies (in $\mathrm{cm}^{-1}$ ) of $\mathrm{C}(2)-\mathrm{O}(3)$ and $\mathrm{C}(2)-\mathrm{O}(4)$ groups in acetylcholine conformers at various theoretical levels $^{a}$

\begin{tabular}{|c|c|c|c|c|c|c|c|c|}
\hline \multirow{2}{*}{ Method } & \multicolumn{4}{|c|}{$\mathrm{C}(2)-\mathrm{O}(3)$} & \multicolumn{4}{|c|}{$\mathrm{C}(2)-\mathrm{O}(4)$} \\
\hline & $\mathrm{C}_{1}$ & $\mathrm{C}_{2}$ & $\mathrm{C}_{3}$ & $\mathrm{C}_{5}$ & $\mathrm{C}_{1}$ & $\mathrm{C}_{2}$ & $\mathrm{C}_{3}$ & $\mathrm{C}_{5}$ \\
\hline B3LYP/6-31G ${ }^{*}$ & $1813(211)$ & $1848(172)$ & $1869(209)$ & $1824(185)$ & $1255(278)$ & $1229(287)$ & $1222(418)$ & $1254(292)$ \\
\hline B3LYP/6-311++G ${ }^{* *}$ & $1789(246)$ & $1819(220)$ & $1838(265)$ & $1797(227)$ & $1225(298)$ & $1205(327)$ & $1199(406)$ & $1224(305)$ \\
\hline $\mathrm{MP} 2 / 6-31 \mathrm{G}^{*}$ & $1820(158)$ & $1841(127)$ & $1857(160)$ & $1824(144)$ & $1281(271)$ & $1258(174)$ & $1250(408)$ & $1286(290)$ \\
\hline MP2/6-311++G ${ }^{* *}$ & 1801(194) & $1818(165)$ & $1836(205)$ & $1800(185)$ & $1245(262)$ & $1232(305)$ & $1219(422)$ & $1252(209)$ \\
\hline MP2/aug'-cc-pVDZ & $1769(178)$ & 1841(139) & 1801(189) & $1768(173)$ & $1239(188)$ & $1230(182)$ & $1207(384)$ & $1242(240)$ \\
\hline
\end{tabular}

${ }^{a}$ Values in parentheses represent the peak intensities. 
three Lorentzian shapes were used to fit the peaks near 1770 $\mathrm{cm}^{-1}$ in the IRMPD spectrum (Fig. 4(c) in ref. 11), although the calculated absorption frequencies and intensities vary somewhat depending upon the level of theory employed, it appears that the conformers corresponding to the three peaks in the IRMPD spectrum in ref. 11 must be, from low to high frequency, $\mathrm{C}_{1}\left(\right.$ or $\left.\mathrm{C}_{5}\right), \mathrm{C}_{2}$, and finally, $\mathrm{C}_{3}$ conformer, respectively, as the peak frequencies are shown to generally follow this order of calculated frequencies of aforementioned conformers. It is worth noting that $\mathrm{C}_{1}$ and $\mathrm{C}_{5}$ appear to have almost the same frequencies at the MP2 level (with larger basis sets), suggesting the lowest peak in the spectrum would correspond to contributions from both $\mathrm{C}_{1}$ and $\mathrm{C}_{5}$ conformers with larger peak intensity than the other remaining peaks. This is in good agreement with the spectral features in ref. 11 (Fig. 4(c)). Furthermore, the calculated intensity of $\mathrm{C}_{3}$ is stronger than the calculated intensity of $\mathrm{C}_{2}$, which also appears to be in good agreement with the spectral features in ref. 11, though the intensities in the IRMPD spectrum do not necessarily correspond to the absorption intensities in the IR spectrum due to the dependence of fragmentation yields on internal vibrational redistribution rates of the vibrational modes involved. Therefore, the spectral features around $1770 \mathrm{~cm}^{-1}$ in the IRMPD spectrum of acetylcholine ion appears to be in accord with our theoretical results about the stability of conformers of acetylcholine ion.

In the case of $\mathrm{C}(2)-\mathrm{O}(4)$ stretching vibration, while the calculated frequencies in Table 5 appear to suggest more than two absorption peaks, the insufficient data points in the IRMPD spectrum (Fig. 4(b) in ref. 11) make it somewhat difficult to identify the accurate peak structures in this region. However, considering that the calculated frequencies of $\mathrm{C}_{1}$ and $\mathrm{C}_{5}$ conformer for $\mathrm{C}(2)-\mathrm{O}(4)$ stretch are very close each other and the difference between the two peaks in Figure 4(b) in ref. 11 is similar to the difference in calculated frequencies of $\mathrm{C}_{1}\left(\right.$ or $\mathrm{C}_{5}$ ) and $\mathrm{C}_{2}$ (or $\left.\mathrm{C}_{3}\right)$, it is suggested that the higher frequency peak should correspond to contributions from $\mathrm{C}_{1}$ and $\mathrm{C}_{5}$, with the lower frequency peak corresponding to contributions from $\mathrm{C}_{2}$ and $\mathrm{C}_{3}$. An IR spectrum of this ion with better resolution than the IRMPD spectrum in ref. 11 would be necessary to make a proper evaluation of the calculated results for $\mathrm{C}(2)-\mathrm{O}(4)$ stretching vibration in Table 5.

\section{Summary and Conclusion}

We have examined the relative stability and interconversion of five lowest energy conformers $\left(\mathrm{C}_{1}, \mathrm{C}_{2}, \mathrm{C}_{3}, \mathrm{C}_{4}\right.$, and $\mathrm{C}_{5}$ ) of acetylcholine ion in gas phase employing B3LYP, $\mathrm{MP} 2$, and $\operatorname{CCSD}(\mathrm{T})$ methods along with diverse basis sets including the correlation consistent aug-cc-pVDZ and augcc-pVTZ sets. Except for $\mathrm{C}_{4}$ lying in much higher energy region than the rest of the conformers, it was found that the energy order of the other conformers can be predicted correctly only when basis set is sufficiently large enough to contain a proper number of polarization and diffuse functions for correlated calculations. On the basis of MP2/aug-cc-pVTZ and $\operatorname{CCSD}(\mathrm{T}) /$ aug'-cc-pVDZ results, the electronic energy of $\mathrm{C}_{5}$ conformer appears to be lower than the electronic energy of $\mathrm{C}_{3}$ by $0.5-1 \mathrm{kcal} / \mathrm{mol}$, in contrast to the previous calculation results with smaller basis sets which suggested more stability for $\mathrm{C}_{3}$ than $\mathrm{C}_{5}$ conformer. The vibrational frequency and thermal contribution calculations also suggests that stability of $\mathrm{C}_{5}$ over $\mathrm{C}_{3}$ would be maintained at room temperature condition as the Gibbs free energy of $\mathrm{C}_{3}$ relative to $\mathrm{C}_{5}$ conformer at $298 \mathrm{~K}$ is shown to be larger by 0.3 to $0.8 \mathrm{kcal} / \mathrm{mol}$ based on at various levels of theory.

The presence of unsuperimposable configurations of mirror image for these conformers $\left(\mathrm{C}_{1}{ }^{\prime} \mathrm{C}_{2}^{\prime}, \mathrm{C}_{3}^{\prime}\right.$, and $\left.\mathrm{C}_{5}{ }^{\prime}\right)$ except $\mathrm{C}_{4}$ would make direct conversion from $\mathrm{C}_{1}$ to $\mathrm{C}_{2}$ (or from $\mathrm{C}_{3}$ to $\mathrm{C}_{5}$ ) difficult to proceed at room temperature without intermediate state of another conformer $\mathrm{C}_{3}$ (or $\mathrm{C}_{1}$ ). Similarly, while interconversion between $\mathrm{C}_{2}$ and $\mathrm{C}_{5}$ is much difficult to occur, $\mathrm{C}_{2}$ appears to change its conformation to $\mathrm{C}_{5}$ ' at room temperature without much difficulty due to the chirality of acetylcholine at room temperature.

The barrier heights between these conformers appear to be greater than $\mathrm{kT}$ at room temperature in most cases, suggesting distinct contributions to the IR spectral structure of acetylcholine ion from these conformers. This appears to be well manifested in the spectral features around $1770 \mathrm{~cm}^{-1}$ in the IRMPD spectrum of acetylcholine ion with which the general pattern of calculated frequencies and peak intensities of relevant conformers are in good accord. It has been suggested ${ }^{11}$ that presence of water molecules would reduce the number of accessible conformations in the case of acetylcholine. Since acetylcholine is known to be in hydrated form in neurotransmission of biological organism, it would be interesting to examine how the conformational energetics and interconversion pathways elucidated in this study would be affected by surrounding water molecules.

\section{References}

1. Yuan, H.; Petukhov, P. A. Bioorg. Med. Chem. 2006, 14, 7936.

2. Cashin, A. L.; Petersson, E. J.; Lester, H. A.; Dougherty, D. A. J. Am. Chem. Soc. 2005, 127, 350.

3. Taylor, P.; Brown, J. H. Acetylcholine. In Brady, S., Siegel, G., W. Albers, R., Price, D., Eds.; Basic Neurochemistry: Molecular, Cellular and Medical Aspects; Academic Press: London, 2005; pp 185-209.

4. Beverige, D. L.; Radna, R. J. J. Amer. Chem. Soc. 1971, 93, 3759.

5. Radna, R. J.; Beveridge, D. L.; Bender, A. L. J. Am. Chem. Soc. 1973, 95, 3831.

6. Beverige, D. L.; Kelly, M. M.; Radna, R. J. J. Am. Chem. Soc. 1974, 96, 3769.

7. Froimowitz, M.; Gans, J. J. Am. Chem. Soc. 1972, 94, 8020.

8. Pullman, A.; Port, G. N. J. Theoret. Chim. Acta 1973, 32, 77.

9. Segall, M. D.; Payne, M. C.; Boyes, R. N. Mol. Phys. 1998, 93, 365.

10. Muñoz-Caro, C.; Niño, A.; Mora, M.; Reyes, S.; Melendez, F. J.; Castro, M. E. Journal of Molecular Structure: THEOCHEM 2005, $726,115$.

11. Seydou, M.; Grégoire, G.; Jean Liquier, Lemaire, J.; Schermann, J. P.; Desfrançois, C. J. Am. Chem. Soc. 2008, 130, 4187.

12. Moller, C.; Plesset, M. S. Phys. Rev. 1934, 46, 618.

13. Pople, J. A.; Head-Gordon, M.; Raghavachari, K. J. Chem. Phys. 1987, 87, 5968 
14. Becke, A. D. J. Chem. Phys. 1993, 98, 5648.

15. Lee, C.; Yang, W.; Parr, R. G. Phys. Rev. B 1988, 37, 785.

16. Vosko, S. H.; Wilk, L.; Nusair, M. Can. J. Phys. 1980, 58, 1200.

17. Stephens, P. J.; Devlin, F.; Chabalowski, C. F.; Frisch, M. J. J. Phys. Chem. 1994, 98, 11623.

18. Kohn, W.; Sham, L. J. Physical Review 1965, 140, A1133.

19. Dunning, T. H., Jr. J. Chem. Phys. 1989, 90, 1007.

20. Kendall, R. A.; Dunning, T. H., Jr.; Harrison, R. J. J. Chem. Phys. 1992, 96, 6796.

21. Gonzalez, C.; Schlegel, H. B. J. Chem. Phys. 1989, 90, 2154.

22. Gonzalez, C.; Schlegel, H. B. J. Phys. Chem. 1990, 94, 5523.

23. Frisch, M. J.; Trucks, G. W.; Schlegel, H. B.; Scuseria, G. E.; Robb, M. A.; Cheeseman, J. R.; Montgomery, J. A., Jr.; Vreven, T.; Kudin, K. N.; Burant, J. C.; Millam, J. M.; Iyengar, S.S.; Tomasi, J.; Barone, V.; Mennucci, B.; Cossi, M.; Scalmani, G.; Rega, N.; Petersson, G. A.; Nakatsuji, H.; Hada, M.; Ehara, M.; Toyota, K.; Fukuda, R.; Hasegawa, J.; Ishida, M.; Nakajima, T.;
Honda, Y.; Kitao, O.; Nakai, H.; Klene, M.; Li, X.; Knox, J. E.; Hratchian, H. P.; Cross, J. B.; Bakken, V.; Adamo, C.; Jaramillo, J.; Gomperts, R.; Stratmann, R. E.; Yazyev, O.; Austin, A. J.; Cammi, R.; Pomelli, C.; Ochterski, J. W.; Ayala, P. Y.; Morokuma, K.; Voth, G. A.; Salvador, P.; Dannenberg, J. J.; Zakrzewski, V. G.; Dapprich, S.; Daniels, A. D.; Strain, M. C.; Farkas, O.; Malick, D. K.; Rabuck, A. D.; Raghavachari, K.; Foresman, J. B.; Ortiz, J. V.; Cui, Q.; Baboul, A. G.; Clifford, S.; Cioslowski, J.; Stefanov, B. B.; Liu, G.; Liashenko, A.; Piskorz, P. Komaromi, I.; Martin, R. L.; Fox, D. J.; Keith, T.; Al-Laham, M. A.; Peng, C. Y.; Nanayakkara, A.; Challacombe, M.; Gill, P. M. W.; Johnson, B.; Chen, W.; Wong, M. W.; Gonzalez, C.; Pople, J. A. Gaussian 03, revision D.01; Gaussian, Inc.: Wallingford, CT, 2004.

24. Grishanin, B. A.; Zadkov, V. N. J. Exper. Theo. Phys. 1999, 89, 669.

25. Elango, M.; Maciel, G. S.; Palazzetti, F.; Lombardi, A.; Aquilanti, V. J. Phys. Chem. A 2010, 114, 9864. 